\title{
Synthesis and characterization of isophorondiamine based epoxy hardeners from aminolysis of PET
}

\author{
L. Kárpáti , M. Fejér, D. Kalocsai, J. Molnár, V. Vargha \\ Department of Physical Chemistry and Materials Science, Laboratory of Plastics and Rubber Technology Budapest \\ University of Technology and Economics, Műegyetem rkp. 3, 1111, Hungary
}

Received 12 December 2018; accepted in revised form 11 February 2019

\begin{abstract}
The solvolysis of poly(ethylene-terephthalate) (PET) is one of the most researched areas in chemical recycling. In this study PET aminolysis with isophorondiamine has been done - in opposition to recent trends - without excess reagent and the raw reaction product was further used without purification. The aminolysis product was thoroughly characterized with nuclear magnetic resonance (NMR) spectroscopy. Isophoronediamine was used as a solvent to prepare amine crosslinker solutions for epoxy resins. The effect of the concentration on the cross-linking reaction and thermomechanical properties were investigated. The curing reaction was found to be significantly accelerated by the presence of the aminolysis product. Both the ethylene-glycol and the terephthal-amide-diamines have a catalytic effect on the reaction. The glass transition temperature decreased with increasing concentrations of the cross-linker solutions due to the decreasing cross-link density. Thus, raw aminolysis products can be utilized for epoxy curing and are advantageous in modifying slower curing cycloaliphatic cross linker systems.
\end{abstract}

Keywords: polymer synthesis, molecular engineering, thermosetting resins, recycling

\section{Introduction}

Plastic recycling is an ever emerging problem in our society. Several methods have been developed to recycle commodity plastics, such as poly(propylene), poly(ethylene), poly(styrene), poly(vinyl-cloride) and poly(ethylene-terephthalate) (PET) [1-6]. With classical remoulding processes like extrusion and injection moulding a significant decrease in mechanical properties cannot be avoided after a certain number of cycles [7-10]. At one point chemical methods should be applied to regain the resources from these materials. Chemical recycling, namely the solvolysis of PET waste is one of the most widely applied and researched methods. The solvolysis reaction, e.g. glycolysis, is a typically slow equilibrium based transesterification reaction that should be carried out at higher temperatures and pressures with higher reagent ratios and a catalyst to obtain pure terephthalic acid derivatives [11-20]. This is not to mention the need for extra purification steps that must be done to regain the ethylene-glycol and to separate the terephthalic acid derivatives. Due to these circumstances, chemical recycling is mostly known as a rather expensive method. Several publications have focused on the catalytic enhancement of bishydroxyethyl terephthalate (BHET) production [11, 13-15, 21]. The aminolysis of PET can occur under less demanding conditions and could be used to gain new value added chemicals and polymeric materials and resins [18, 20, 22-29]. Epoxy curing with PET aminolysis products is still an expanding field that only a few studies have focused on [19, 30]. Most of these utilized aliphatic diamines and applied several cleaning steps to gain pure terephtalic-amides and remove the ethylene-glycol side products. In several early publications the catalytic effects of hydroxyl groups in

${ }^{*}$ Corresponding author, e-mail: karpati.levente@mail.bme.hu (C) BME-PT 
epoxy curing reactions with amine cross-linkers were tested and proved [31-33]. Thus if, ethylene glycol (EG) is not removed from the raw aminolysis product it could serve as a catalyst via hydrogen bond formation for the cross-linking reactions. Since a hydrogen bond is required for this kind of catalytic effect $[33,34]$, the amide groups of the terephthalamide-diamines could also provide a catalytic acceleration as well. Up to this point no research groups have attempted to use the raw aminolysis products of PET for epoxy curing and exploring their catalytic effects.

In this study our goal was to investigate the use of raw aminolysis products of PET as epoxy curing agents, characterize the cross-linked resins, and develop an industrially easily applicable method for diamine curing agent production.
In this study a widely used cycloaliphatic epoxy hardener, isophoron-diamine (IPD) was used in PET aminolysis to produce terephthalic-amide-diamines (Figure 1). The aminolysis was carried out without excess IPD (1:2 ester- to amine group mol ratio). The chemical structure was identified, with ${ }^{1} \mathrm{H},{ }^{13} \mathrm{C}$, distortionless enhancement by polarization transfer (DEPT), ${ }^{1} \mathrm{H}-{ }^{13} \mathrm{C}$ heteronuclear single quantum coherence (HSQC), ${ }^{1} \mathrm{H}-{ }^{13} \mathrm{C}$ hetero-nuclear multiplequantum coherence (HMBC), ${ }^{1} \mathrm{H}-{ }^{15} \mathrm{~N}$ HMBC, ${ }^{1} \mathrm{H}-{ }^{1} \mathrm{H}$ correlated spectroscopy (COSY), and ${ }^{1} \mathrm{H}-{ }^{1} \mathrm{H}$ nuclear Overhauser effect spectroscopy (NOESY) nuclear magnetic resonance spectroscopy (NMR) measurements. The raw reaction product was dissolved in IPD $(0-50 \mathrm{~m} / \mathrm{m} \%)$ to gain an easy to handle, low temperature curing epoxy hardener system. The effect of the terephthal-amide-diamine concentration was<smiles>COC(=O)c1ccc(C(=O)OCCC(C)O)cc1</smiles><smiles>CC1(C)CC(N)CC(C)(CNC(=O)c2ccc(C(=O)NC3CC(C)(C)CC(C)(CN)C3)cc2)C1</smiles>
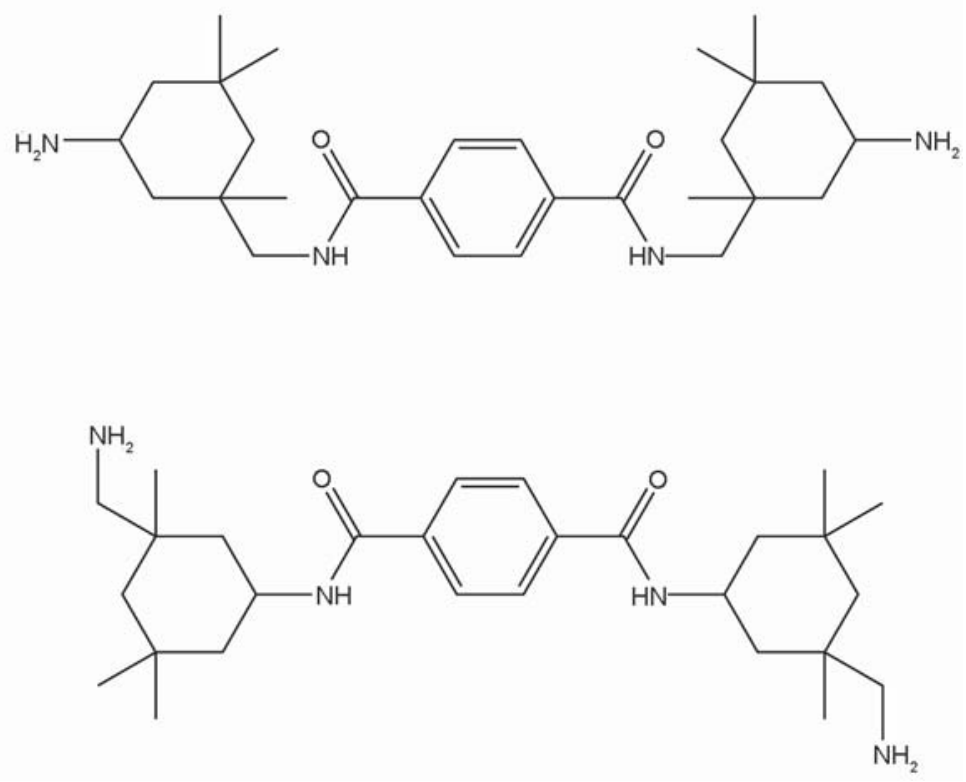

Figure 1. The aminolysis reaction of PET with isophoron-diamine. 


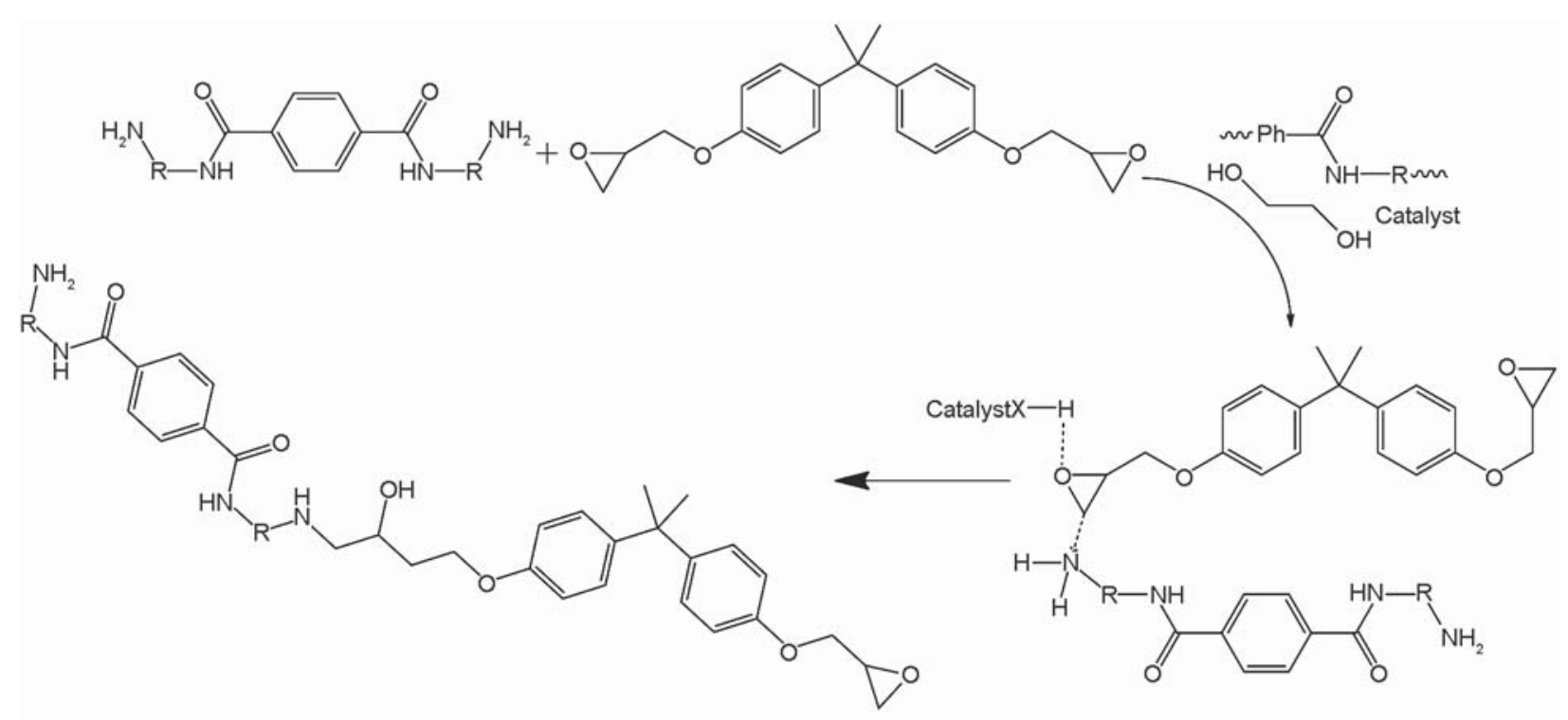

Figure 2. The catalyzed reaction of bisphenol A diglycidilether with terephthalic-amide-diamines.

investigated on the cross-linking reaction (Figure 2), gelation, thermomechanical, and mechanical properties of the cured epoxy resins.

\section{Experimental section}

\subsection{Materials}

PET granules made by DSM Arnite ${ }^{\circledR}$ D00 301 (DSM, Heerleen Netherlands) were used for the aminolysis reactions. Bisphenol A-diglicidylether IPOX ${ }^{\circledR} \mathrm{EH}$ 1010 epoxy resin (EE: $180-196 \mathrm{~g} \cdot \mathrm{mol}^{-1}, \eta: 10000$ $14000 \mathrm{mPa} \cdot \mathrm{s}, \rho: 1.17 \mathrm{~g} \cdot \mathrm{cm}^{-3}$ ) and Isophorone-diamine ER 2943 (IPD) (Amin value: 645$675 \mathrm{mg} \mathrm{KOH} \mathrm{g}{ }^{-1}, \eta: 5-25 \mathrm{mPa} \cdot \mathrm{s}, \rho: 0.92 \mathrm{~g} \cdot \mathrm{cm}^{-3}$, $\sim 90 \%$ pure (HPLC)) were purchased from Ipox Chemicals (Budapest, Hungary). Zinc-acetate $\left(\mathrm{Zn}(\mathrm{OAc})_{2} \cdot 2 \mathrm{H}_{2} \mathrm{O}\right)$ was purchased from BDH Chemicals (VWR International, Radnor, USA). $N, N$-dimethyl-formamide (99\%, 06120-203-340) (DMF), pyridine $(99 \%, 08160-203-340)$, potassium hydroxide (99\%, 04300-101-190) and hydrochloric acid (37\%, 08710-006-340) were purchased from Molar Chemicals (Halásztelek, Hungary). Phthalic anhydride (99\%, A14955) was purchased from AlfaAesar. Deuterated dimethylsulfoxide (DMSO- $\left.d_{6}\right)(99.9 \%$, 15874-10X1ML) was purchased from Sigma-Aldrich (Saint Luis, USA).

\subsection{Aminolysis of PET with IPD}

The aminolysis of PET was carried out in a $250 \mathrm{~cm}^{3}$ four-necked round-bottom glass flask equipped with a thermometer, a gas inlet, a reflux condenser, and a mechanical stirrer. The reaction mixture was heated to $200^{\circ} \mathrm{C}$ and was kept there for 4 hours in argon atmosphere. $80 \mathrm{~g}$ of the PET granules and $0.8 \mathrm{~g}$ of zinc acetate transesterification catalyst ( $1 \%$ of PET) were added. The applied IPD ratio (1:2) was calculated from the ester group content of the PET. At the end of the reactions the homogenous, viscous, greenyellow melt was poured into an aluminum pan. The reaction yields were near $90 \%$.

\subsection{Reaction product characterization}

The amine and hydroxyl functional group content was determined via titration methods. 0.1-0.2 g samples with analytical balance were weighed in an Erlenmeyer flask and dissolved in $15 \mathrm{~cm}^{3}$ of DMF. The 3 samples and a blank sample were titrated with a $0.1 \mathrm{M}$ hydrochloric acid solution in the presence of a bromocresole green indicator to determine the amine content of the samples. The hydroxyl group content was determined with a back titration method. 3 samples of $1.3 \mathrm{~g}$ were weighed in Erlenmeyer flasks with analytical precision. $25 \mathrm{~cm}^{3}$ of $1 \mathrm{M}$ phthalic anhydride solution in pyridine was added to the 3 samples and to the blank sample. The samples were heated to $110^{\circ} \mathrm{C}$ in oil-baths and were refluxed for 2 hours. After the samples cooled to room temperature, $50 \mathrm{~cm}^{3}$ pyridine was added through the condenser. The samples were titrated with a $0.5 \mathrm{M} \mathrm{NaOH}$ solution in the presence of a phenolphthalein indicator.

Perkin Elmer TGA 6 (PerkinElmer, Waltham, USA) was used to determine the thermal stability of the reaction product, and the cured epoxy specimens in purging nitrogen gas. A $10 \mathrm{mg}$ sample was heated 
with a $10^{\circ} \mathrm{C} \cdot \mathrm{min}^{-1}$ heating rate from $30-700^{\circ} \mathrm{C}$, then the sample was kept at $700^{\circ} \mathrm{C}$ for 10 minutes in oxygen atmosphere.

A Brucker Tensor 27 FTIR spectrometer (Bruker, Billerica, USA) was used to measure the FTIR spectra of the reaction products in $\mathrm{KBr}$ pastilles (28 scans, 4000-400 $\left.\mathrm{cm}^{-1}\right) .{ }^{1} \mathrm{H},{ }^{13} \mathrm{C}$, DEPT, ${ }^{1} \mathrm{H}-{ }^{1} \mathrm{H} \mathrm{COSY}$, ${ }^{1} \mathrm{H}-{ }^{1} \mathrm{H}$ NOESY, ${ }^{1} \mathrm{H}-{ }^{13} \mathrm{C}$ HSQC and ${ }^{1} \mathrm{H}-{ }^{13} \mathrm{C}$ HMBC spectra were recorded with a Bruker Avance 300 spectrometer. ${ }^{1} \mathrm{H}-{ }^{15} \mathrm{~N}$ HMBC spectrum was recorded with a Bruker Avance 500 spectrometer. The samples were dissolved in DMSO- $d_{6}(99 \%)$. The sample concentration was $29 \mathrm{mg} \cdot \mathrm{cm}^{-3}$ for the IPD and $51 \mathrm{mg} \cdot \mathrm{cm}^{-3}$ for the reaction product. The temperature of acquisition was $30^{\circ} \mathrm{C}$.

\subsection{Test specimen preparation and characterization}

A solution series of the aminolysis product and IPD was prepared to use as the cross-linking agent for epoxy resins. The reaction product was dissolved in IPD in different concentrations $(0,5,10,20,30,40$, and $50 \mathrm{~m} / \mathrm{m} \%$ ). The components were weighed with analytical accuracy. The solutions were prepared in round-bottom flasks equipped with a reflux condenser. The flasks were heated to $100^{\circ} \mathrm{C}$ for 30 minutes. The amine value was determined as previously described.

The epoxy content of the ER1010 epoxy resin was measured with a back-titration method. Three samples of $0.2 \mathrm{~g}$ were weighed in Erlemeyer flasks with analytical precision. $16 \mathrm{~cm}^{3}$ concentrated hydrochloric acid (37\%) was dissolved in pyridine to obtain the pyridine hydrochloride solution in pyridine. The samples were dissolved in $25 \mathrm{~cm}^{3}$ solution of pyridine hydrochloride in pyridine. The solutions were heated and let to reflux for 1 hour. After the samples cooled to room temperature $10 \mathrm{~cm}^{3}$ water was added through the condenser. A $0.1 \mathrm{M}$ sodium hydroxide (in methanol) solution was used to titrate the samples in the presence of a phenolphthalein indicator. The mixing ratios for the ER1010 epoxy resin and the cross-linker were calculated according to the stoichiometric ratio.

The epoxy mixture was prepared according to the calculated mixing ratios. The resin and the cross linker were mixed with a glass rod for three minutes in a plastic cup. The plastic cup was placed in a vacuum chamber for 30-40 minutes until the resin was bubble free. $75 \times 4 \times 1.4 \mathrm{~mm}$ 'dogbone' shaped specimens and $50 \times 10 \times 4$ prismatic shaped specimens were moulded for mechanical tests. The specimens were cross-linked for 2 hours at $90^{\circ} \mathrm{C}$ in a VWR VentiLine 115 drying oven (VWR International, Radnor, USA).

PerkinElmer DSC7 (PerkinElmer, Waltham, USA) was used to measure the exothermic entalphy of the cross-linking and the glass transition temperature $\left(T_{\mathrm{g}}\right)$ of the mixtures. The $10 \mathrm{mg}$ of the freshly mixed resin samples were weighed with analytical accuracy. The samples were kept at $30^{\circ} \mathrm{C}$ for $0.5 \mathrm{~min}$, then they were heated to $90^{\circ} \mathrm{C}$ with $200^{\circ} \mathrm{C} \cdot \mathrm{min}^{-1}$ heating rate. The samples were cross-linked at $90^{\circ} \mathrm{C}$ for 2 hours, then the samples were cooled to $0^{\circ} \mathrm{C}$ with $20^{\circ} \mathrm{C} \cdot \mathrm{min}^{-1}$ cooling rate. The reaction heat was calculated from the integration of the isothermal segment between 0 and $30 \mathrm{~min}$. To determine the glass transition temperature $\left(T_{\mathrm{g}}\right)$, the samples were further heated from 0 to $250^{\circ} \mathrm{C}$ with $20^{\circ} \mathrm{C} \cdot \mathrm{min}^{-1}$, kept at $250^{\circ} \mathrm{C}$ for 1 minute, then cooled to $0^{\circ} \mathrm{C}$ with $20^{\circ} \mathrm{C} \cdot \mathrm{min}^{-1}$ and kept there for 1 minute. Then the samples were heated with $20^{\circ} \mathrm{C} \cdot \mathrm{min}^{-1}$ heating rate to $250^{\circ} \mathrm{C}$. The $T_{\mathrm{g}}$ was determined from the last heating period. All the calculations and evaluations were carried out in Pyris Software.

PerkinElmer Diamond DMA (PerkinElmer, Waltham, USA) was used to characterize the glass transition temperature and viscoelastic behavior of the epoxy specimens. A tension test method was used from 20 to $200^{\circ} \mathrm{C}$ with $2^{\circ} \mathrm{C} \cdot \mathrm{min}^{-1}$ heating rate, $1 \mathrm{~Hz}$ frequency and $10 \mu \mathrm{m}$ amplitude. The $T_{\mathrm{g}}$ was determined from the peak of $\tan \delta$. The dogbone shaped specimens were cut to a prismatic shape before the DMA measurements.

Rheological measurements for gel point determination were carried out using an Anton-Paar Physica MCR 301 (Anton Paar GmbH, Graz, Austria) apparatus at $40^{\circ} \mathrm{C}$ in continuous rotation mode with a plate-plate system (plate distance $1 \mathrm{~mm}$ ).

Standard tensile tests were conducted on an Instron 5566 type equipment (Instron Co., Canton, USA) with $5 \mathrm{~mm} \cdot \mathrm{min}^{-1}$ rate to determine the Young's modulus, tensile strength, and elongation at break. Instrumented impact testing was used to investigate the impact resistance. The measurements were carried out with a Ceast Resil 5.5 instrument (CEAST spa, Pianezza, Italy). The impact test specimens were V-notch type samples. All the mechanical tests were done at $23^{\circ} \mathrm{C}$ in an air conditioned laboratory with $50 \%$ air humidity. 


\section{Results and discussion}

\subsection{Aminolysis product characterization}

Functional group analysis was used to characterize the raw reaction product (Table 1). The measured amine value approximates the theoretical amine value $\left(4.24 \mathrm{mmol} \cdot \mathrm{g}^{-1}\right.$, calculated from the theorized

Table 1. Functional group content of IPD and the aminolysis product.

\begin{tabular}{|l|c|c|}
\hline \multicolumn{1}{|c|}{ Material } & $\begin{array}{c}\text { Amine value } \\
{\left[\mathbf{m m o l} \cdot \mathbf{g}^{-\mathbf{1}}\right]}\end{array}$ & $\begin{array}{c}\text { Hydroxyl value } \\
{\left[\mathbf{m m o l} \cdot \mathbf{g}^{-\mathbf{1}} \text { ] }\right.}\end{array}$ \\
\hline IPD & $11.57 \pm 0.041$ & - \\
\hline PET:IPD 1:2 & $3.89 \pm 0.009$ & $3.98 \pm 0.407$ \\
\hline
\end{tabular}

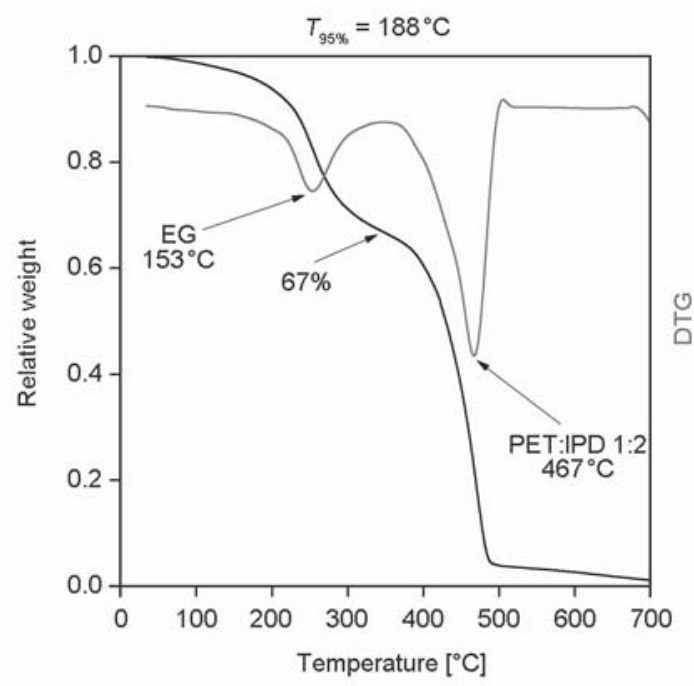

Figure 3. The TGA and DTG curves of PET:IPD 1:2 raw aminolysis product. molecular structure of the product). It suggests the presence of longer terephthalic-acid and isophorondiamine derivative oligoamides. The hydroxyl value was determined to measure the amount of ethylene glycol in the raw product. It was found to be near $100 \%$ based on the PET repeating units. This indicated the complete amidation of the ester groups.

Thermo-gravimetric analysis (TGA) was used to investigate the mass composition and thermal stability of the reaction product (Figure 3). A two-step weight loss process was observed. At the first step the ethylene-glycol content evaporated out of the product resulting in over $30 \%$ weight loss. The thermal degradation of the main reaction product started above $400^{\circ} \mathrm{C}$.

FTIR spectroscopy was used to determine the general molecular structure of the reaction product (Figure 4). The spectra of PET and IPD were added as a reference. The wide peak between $3600-3200 \mathrm{~cm}^{-1}$ are attributed to the valence vibration of the $\mathrm{N}-\mathrm{H}$ (amine and amide) and $\mathrm{O}-\mathrm{H}$ groups. The shoulder/ peak at $3100-3080 \mathrm{~cm}^{-1}$ is attributed to the aromatic, the peaks at 2951 and $2921 \mathrm{~cm}^{-1}$ are attributed to aliphatic/cyclo-aliphatic $\mathrm{C}-\mathrm{H}$ valence vibrations. The peaks at 1638 and $1550 \mathrm{~cm}^{-1}$ are attributed to the amide carbonyl vibrations. Most of the peaks between $1500-1000 \mathrm{~cm}^{-1}$ can be attributed to the bending and skeletal vibrations of the aliphatic and the aromatic hydrocarbon groups. No peaks were found

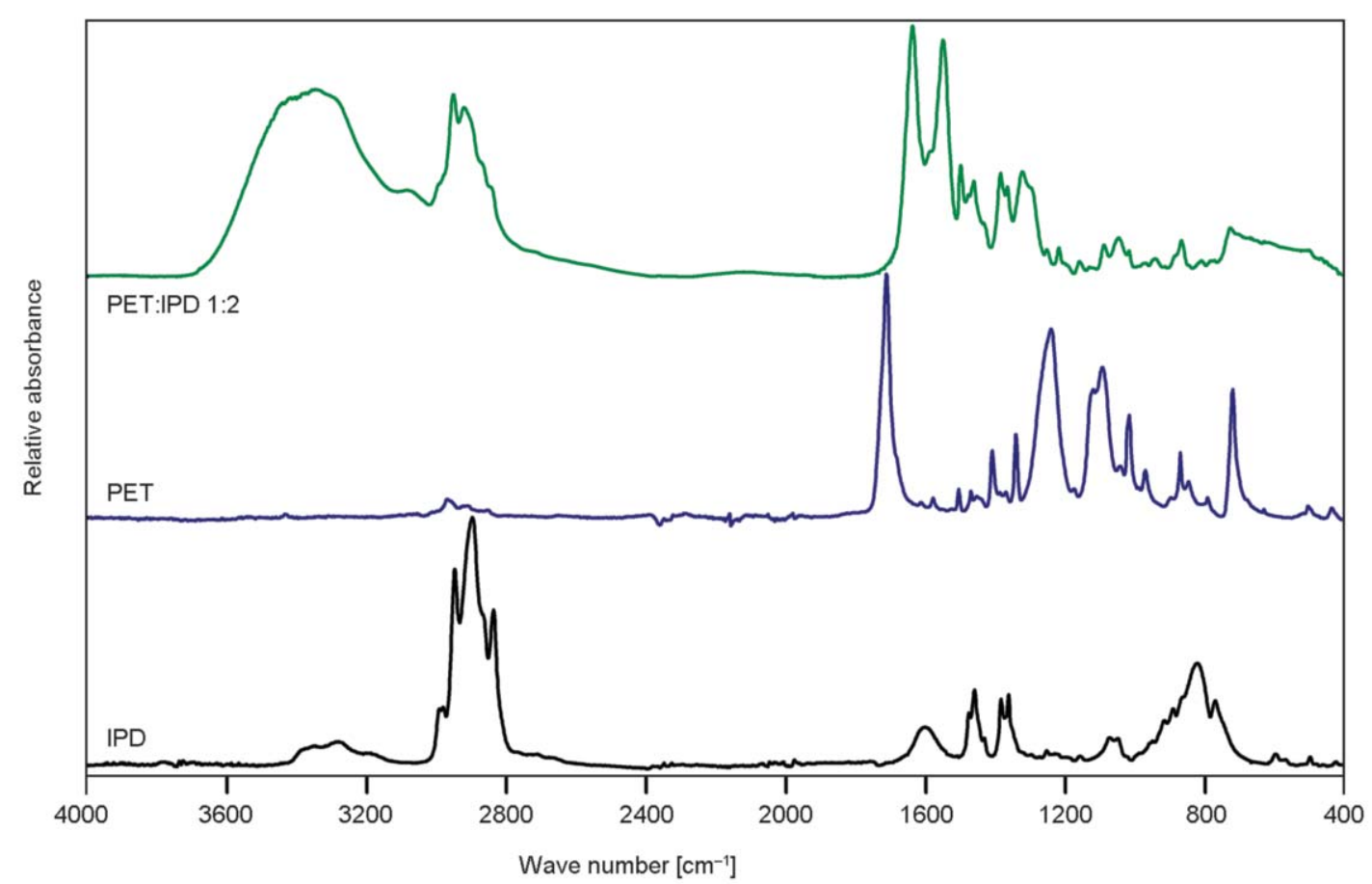

Figure 4. The FTIR spectrum of PET:IPD 1:2. 
that could be attributed to the ester type vibration ( $\sim 1740-1720$ carbonyl vibration, $\sim 1240 \mathrm{~cm}^{-1}$ for $\mathrm{C}-\mathrm{O}-\mathrm{C}$ vibrations). Thus, the amidation of PET was complete and no ester linkages are present in the product.

\subsection{IPD and product characterization with NMR}

Full assignment was carried out on both the IPD and the reaction product. The NMR spectra of the IPD served as a reference for the reaction product assignment (Figure 5, Figure 6). The used IPD is about $90 \%$ pure, thus impurity attributed peaks and peak widening were expected to be observed in the spectra. Several peaks attributed to the contaminant were identified in the ${ }^{13} \mathrm{C}$ spectra. Based on the DEPT and the HSQC spectra the main contaminant is similar to IPD and was identified as 5-(aminomethyl)-3,3-dimethylcyclohexanamine. IPD has two different groups: an aliphatic and a cyclo-aliphatic type amine group that can react during the aminolysis reaction. The results indicate that due to the steric hindrance of the cycloaliphatic connection the reactivity of these groups differ. Thus, aliphatic connected amide groups are

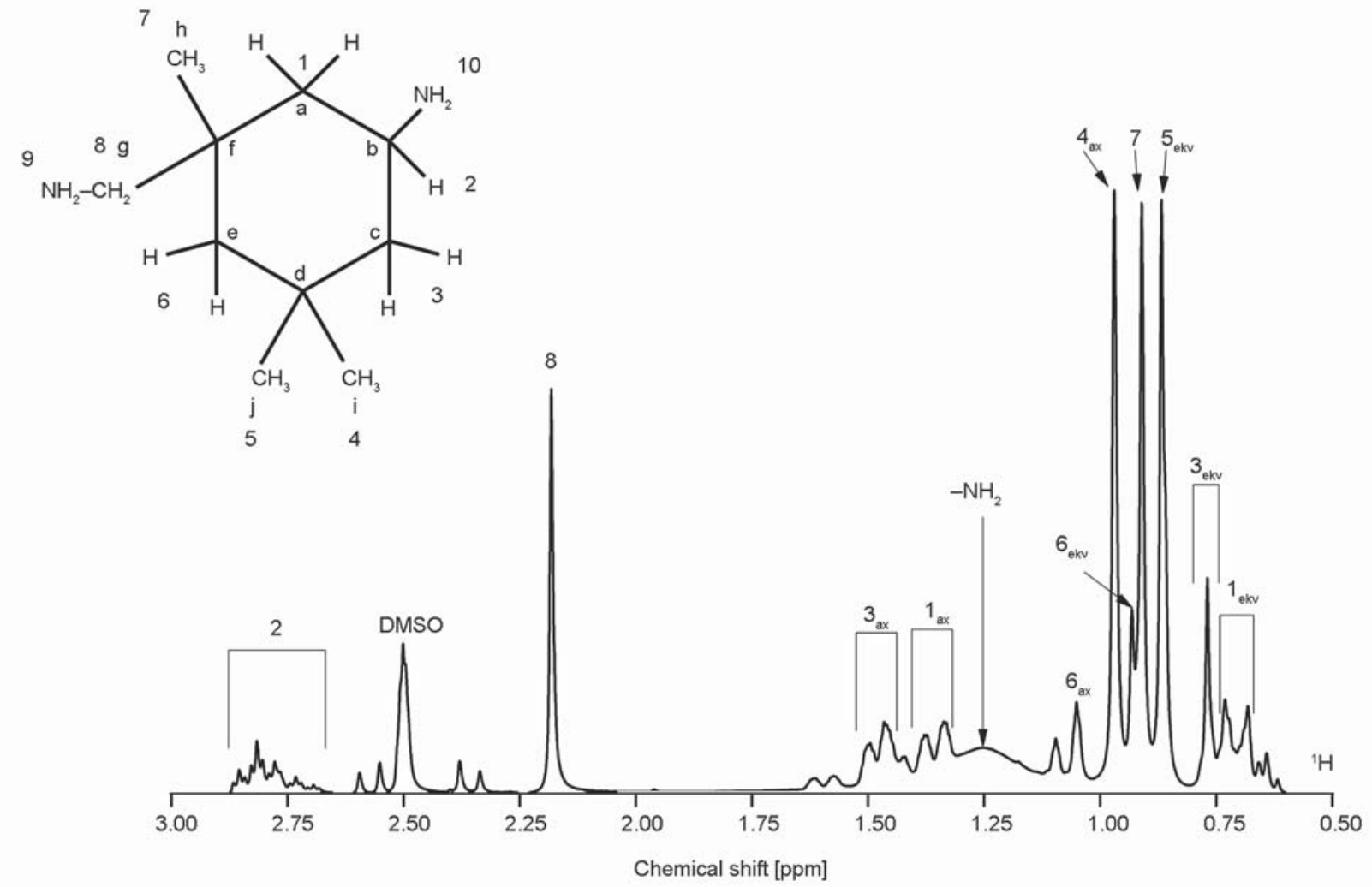

Figure 5. The ${ }^{1} \mathrm{H}$ spectrum and atom numbering of IPD (IPOX EH2293). ${ }^{1} \mathrm{H}$ (numbers) and ${ }^{13} \mathrm{C}$ (alphabet). expected to form. Amide and aromatic related peaks appeared in the ${ }^{1} \mathrm{H}$ and ${ }^{13} \mathrm{C}$ spectra that signaled the success of the amidation (Figure 7, Figure 8). Several low intensity peaks can be observed between the 60-20 ppm interval in the ${ }^{13} \mathrm{C}$ NMR spectrum. These peaks can be attributed to the chemical shift differences between aliphatic or cycloaliphatic connected amides. The most illustrative example is the peaks attributed to the $4 \mathrm{i}_{\mathrm{ax}}, 5 \mathrm{j}_{\mathrm{ekv}}$ and $7 \mathrm{~h}$ methyl groups in both the ${ }^{13} \mathrm{C}$ and ${ }^{1} \mathrm{H}$ spectra. In the ${ }^{13} \mathrm{C}$ spectra new peaks appeared close to the high intensity peaks, in the ${ }^{1} \mathrm{H}$ spectra secondary peaks appeared between the 1.2-0.8 ppm interval.

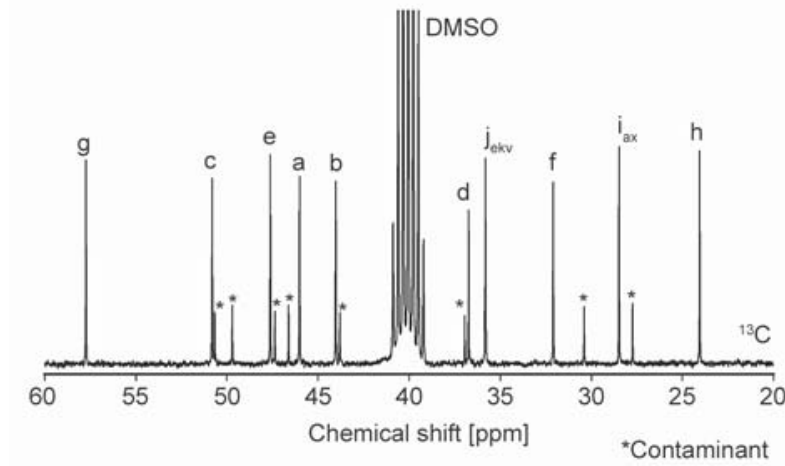

Figure 6. The ${ }^{13} \mathrm{C}$ spectrum of IPD (EH 2293). 


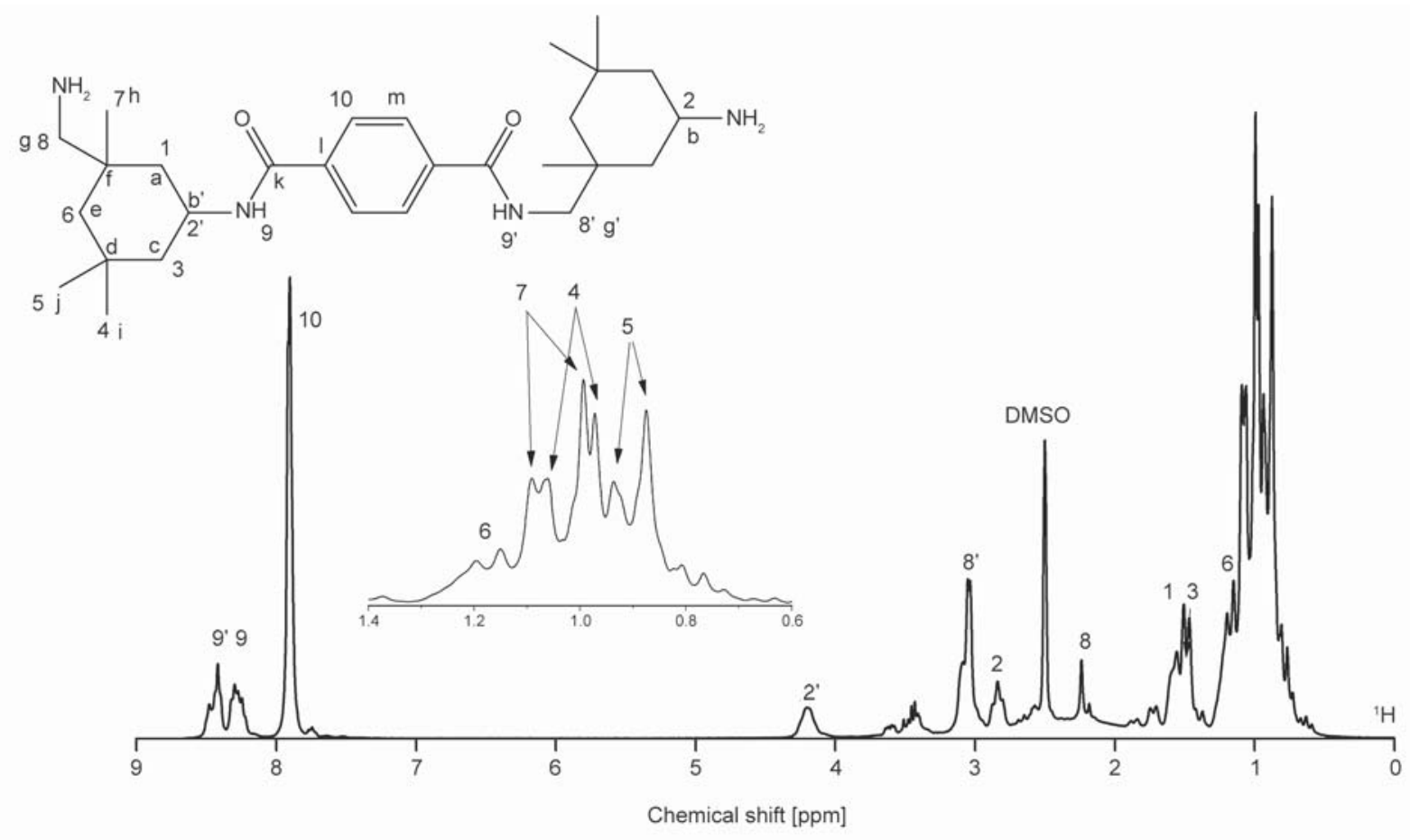

Figure 7. The ${ }^{1} \mathrm{H}$ NMR spectrum and the atom numbering of PET:IPD 1:2.

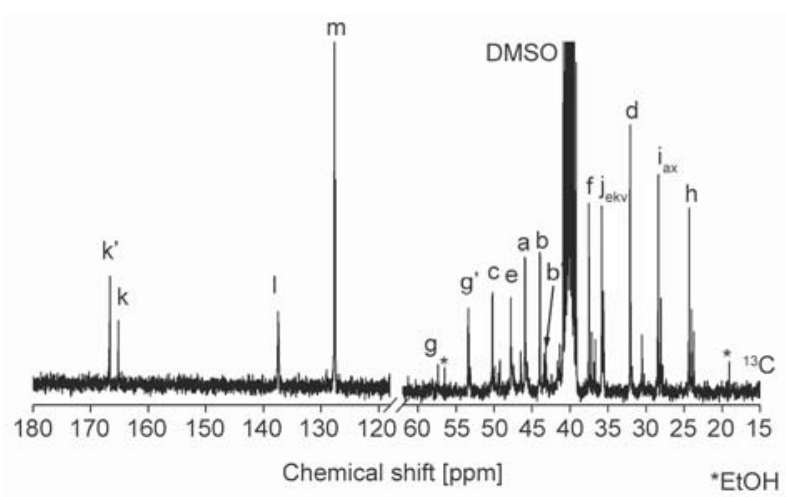

Figure 8. The ${ }^{13} \mathrm{C}$ NMR spectrum of PET:IPD 1:2.

\subsection{Cross-linker system design, solubility calculations}

The aminolysis reactions yielded a green-yellow coloured, amorphous, brittle material that slowly softened and melted between $100-150^{\circ} \mathrm{C}$. Thus, the produced terephthalic amides could not be used directly as hardeners in conventional low cure temperature epoxy resin systems. Our purpose was to gain a cross-linker system that could be processed at room temperature. Therefore, solubility parameters were calculated using the Fedor's group contribution calculation method to find possible solvents for the crosslinking agent [35] (Table 2). The raw terephthalicamides were found to dissolve in DMF, DMSO, ethanol, isopropanol and IPD.
Table 2. Calculated solubility parameters and cohesion energy density data.

\begin{tabular}{|l|c|c|c|}
\hline & $\begin{array}{c}\boldsymbol{V}_{\mathbf{m}} \\
{\left[\mathbf{m o l} \cdot \mathbf{c m}^{-3}\right]}\end{array}$ & $\begin{array}{c}\boldsymbol{E}_{\mathbf{c o h}} \\
{\left[\mathbf{J}_{\mathbf{c m}} \mathbf{- 3}\right]}\end{array}$ & $\begin{array}{c}\boldsymbol{\delta} \text { (Fedors) } \\
{\left[\mathbf{M P a}^{\mathbf{1} / \mathbf{2}}\right]}\end{array}$ \\
\hline IPD & 163.90 & 65380 & 20.0 \\
\hline PET:IPD 1:2 & 328.60 & 194680 & 24.3 \\
\hline DMF & 70.90 & 37050 & 22.8 \\
\hline DMSO & 77.80 & 48560 & 25.0 \\
\hline EtOH & 58.40 & 39450 & 26.0 \\
\hline iPrOH & 76.34 & 42650 & 23.6 \\
\hline
\end{tabular}

The major problem (except IPD) with these solvents was that most of them could only be used as a nonreactive solvent. During the hardening process these solvents could only act as a viscosity reducing agent and could not react with the epoxy resin. Due to the low amine value of the reaction product, the high amount of unreactive solvents would swell the crosslinked resin to an 'organo-gel' like state. These solvents would only act as a reaction medium, and would need to be removed from the final product. IPD is a widely used epoxy cross-linker, it can react with epoxy groups and become part of the resin structure. In addition, the cross-linker solutions with IPD could be easily prepared by introducing excess IPD at the end of the aminolysis process. Thus, the reaction product was dissolved in IPD and was utilized as a cocuring agent. Due to its chemical structure (longer 
Table 3. Measured amine and calculated EG content of the cross-linker solution.

\begin{tabular}{|c|c|c|}
\hline & $\begin{array}{c}\text { Amine value } \\
{\left[\mathbf{m m o l} \cdot \mathbf{g}^{-1}\right]}\end{array}$ & $\begin{array}{c}\text { OH value } \\
{\left[\mathbf{m m o l} \cdot \mathbf{g}^{-1} \text { ] }\right.}\end{array}$ \\
\hline $0 \%$ & $11.67 \pm 0.034$ & 0.00 \\
\hline $5 \%$ & $11.05 \pm 0.027$ & 9.95 \\
\hline $10 \%$ & $10.80 \pm 0.035$ & 19.9 \\
\hline $20 \%$ & $9.98 \pm 0.014$ & 39.8 \\
\hline $30 \%$ & $9.19 \pm 0.005$ & 59.7 \\
\hline $40 \%$ & $8.47 \pm 0.022$ & 79.6 \\
\hline $50 \%$ & $7.67 \pm 0.020$ & 99.5 \\
\hline
\end{tabular}

molecule), the usage of the terephthal-amide-diamines could lower the cross-link density in the final epoxy resins. A cross-linker solution sequence of 0 to 50 weight $\%$ was prepared and was used in this study to characterize our reaction product as a crosslinker. The amine value of the solutions followed a linearly declining tendency with increasing concentration (Table 3). The EG concentration of the crosslinker solutions was calculated based on the hydroxyl group content of the raw product. The mixing ratios were calculated, and several samples were prepared to study the thermal, thermomechanical, and mechanical properties of the epoxy resin systems.

\subsection{Cross-linking characterization}

Calorimetric and rheological measurements were carried out to characterize the cross-linker solution during curing reactions. The exothermic reaction heat was calculated from the integration of isothermal curing curves. Due to the similarity of the amine groups on IPD and the reaction product, a similar reaction rate is expected. Any differences in the reaction rate,

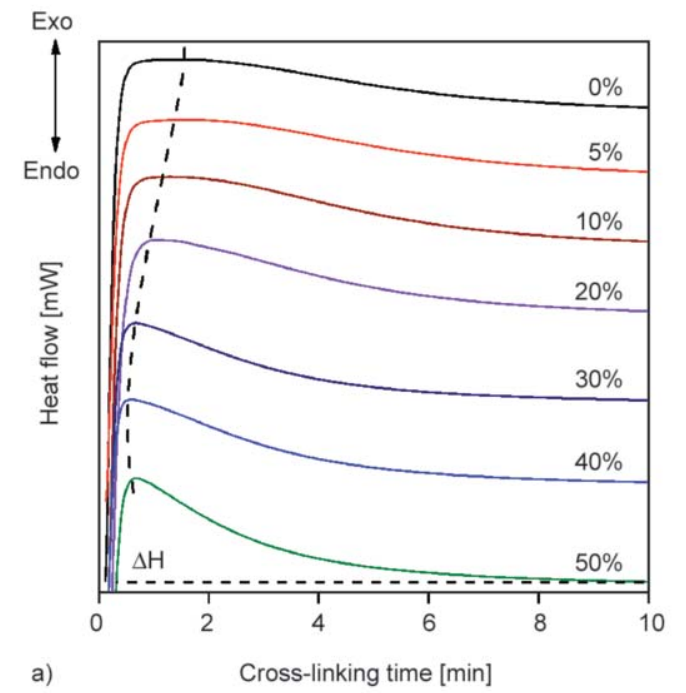

compared to IPD, must be the result of the amidation and the catalytic effect of the EG and the terephthalamide content. Several reaction processes can take place during the curing of epoxy resins with diamines. In our case these are the uncatalyzed reaction - the auto-catalyzed reaction -; by secondary hydroxyl groups; the catalyzed reaction by hydroxyl (EG) or amide groups; and the reaction of hydroxyl and epoxy groups $[33,34]$. Inasmuch as the reaction catalyzed by ethylene-glycol and the terephthal-amidediamines should be significantly faster and more dominant than the rest of the reaction processes. A clear increasing tendency in the reaction heat, and the peak time was observed as a function of the concentration of the cross-linker solution (Figure 9b). The initial peak during the isothermal step became well-defined. The time to reach the maximum of the heat flow curve decreased with a near linear tendency from 90 to 30 seconds. The heat flow curve reached a plateau sooner (Figure 9a). These observations indicated the intensification of the reaction process with increasing concentration.

Rheological studies were conducted at $50^{\circ} \mathrm{C}$ to measure and characterize the reaction kinetics and determine the gelation point of the resins. The curing reaction was slower at $50^{\circ} \mathrm{C}$ and allowed a more precise measurement. Measuring the gelation at $90^{\circ} \mathrm{C}$ was attempted ( $\sim 2$ min for $20 \%$ solution), but the fast reaction rate (near complete curing) endangered the instrument. The increased concentration of the crosslinker solutions resulted in faster cure rates, shift of the gelation (Figure 10), and the increase in the initial viscosity (Figure 11a). The gel time was attributed

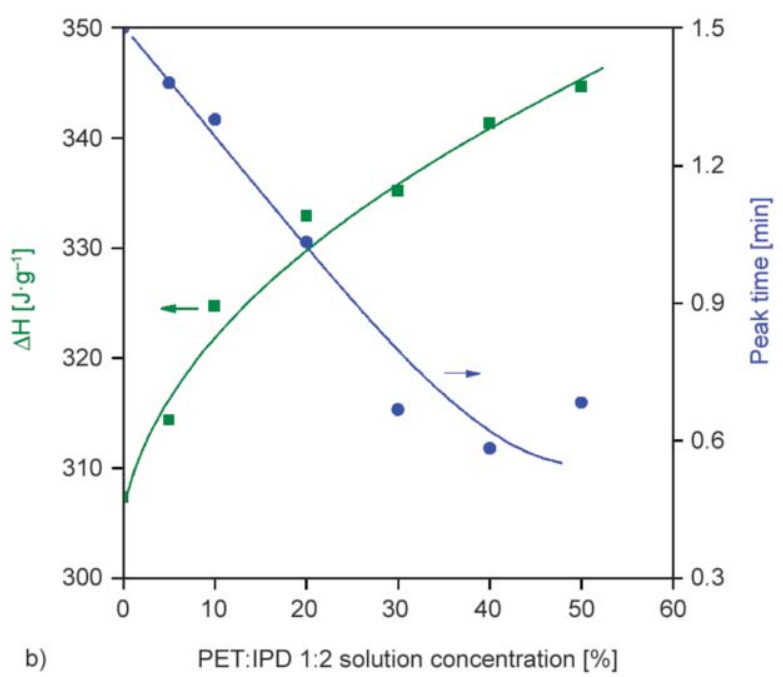

Figure 9. Isothermal curing curves registered with DSC (a), the reaction enthalphy and the time belonging to the maximum (peak) of the isothermal curves. 


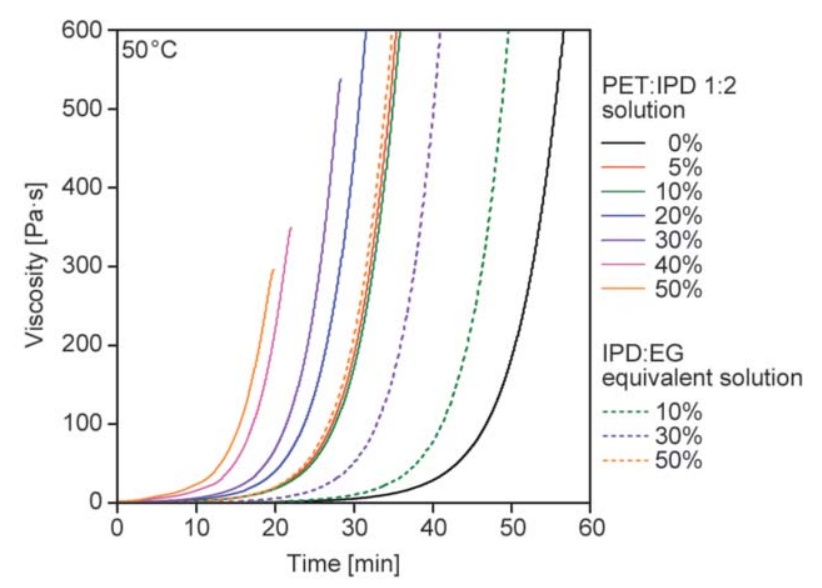

Figure 10. The time dependence of viscosity during curing with PET:IPD 1:2 solutions (solid lines) and equivalent IPD EG solutions (dashed lines).

to the cross point of fitted linear curves on the initial and precipitous parts of the curve. The gel time showed a significant $20 \mathrm{~min}$ decrease from 0 to $5 \%$ solution concentration, then it was followed by a linear decreasing tendency with the increasing solution concentration (Figure 11b). The significant decrease between the $0-5 \%$ points clearly demonstrates the catalytic effect of the aminolysis product. Even 5\% of the product accelerates the reaction. To demonstrate, and model the catalytic effect of EG, three cross-linker solutions of EG in IPD were prepared and their gelation point was measured. The concentration of EG in these was based on the calculated amine/hydroxyl mol-ratio of the PET:IPD 1:2 solutions. Equivalents to the 10,30 and $50 \%$ solutions were prepared. The gelation of these samples was faster than the $0 \%$ (IPD) as expected, but only the $50 \%$

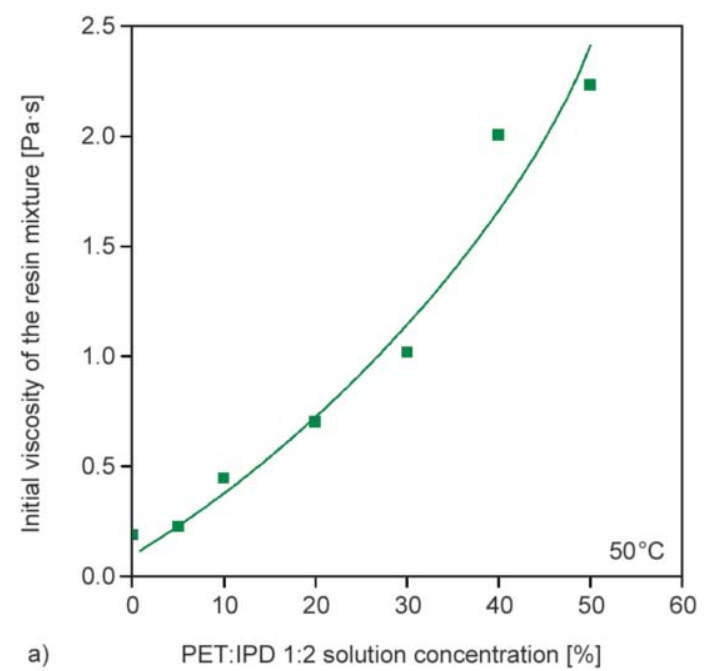

equivalent solution reached the reaction rate of the 5\% PET:IPD 1:2 solution (Figure 10 and Figure 11b). Since a strong hydrogen bond is needed between a glycidyl-ether and the catalyst, not just the EG, but the amide groups of the terephthal amide diamines act as catalysts during the curing reaction. The catalytic effect of terephthal amide diamines gives significant, additional acceleration to the curing reaction. Even at small amounts terephthal-amide-diamines could act as modifiers for cycloaliphatic curing agents to accelerate the curing. Due to the faster curing rate of these systems a more perfect crosslinked structure is expected to form at the same conditions. This was further inspected with dynamic mechanical analysis (DMA).

\subsection{Thermomechanical analysis}

Thermomechanical measurements were conducted via dynamic mechanical analysis (DMA). The dogbone shaped test specimens were moulded, crosslinked at $90^{\circ} \mathrm{C}$ for two hours. The specimens were cut to prismatic shape before measurements. 3-3 parallel specimen were tested. The storage modulus varied between $2.5-3.5 \mathrm{MPa}$ at $30^{\circ} \mathrm{C}$ for every sample (Figure 12a). The differences of the specimens must come from the sample preparation. The storage modulus continuously decreased by increasing the measuring temperature. A major change in slope occurred above $100^{\circ} \mathrm{C}$ that indicated the approximation of the glass transition temperature. Another change of slope around $130^{\circ} \mathrm{C}$ occurred that indicated that a not perfect cross-linked structure formed during the curing of the specimens. Both the loss modulus and the $\tan \delta$

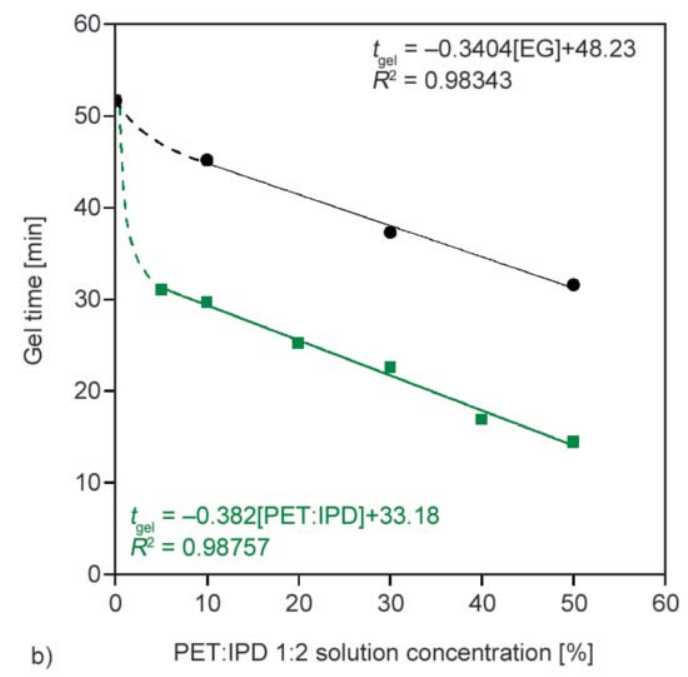

b)

Figure 11. The initial viscosity of the resin mixtures (a) and the calculated gel times for PET:IPD 1:2 and IPD-EG model solutions (b). 

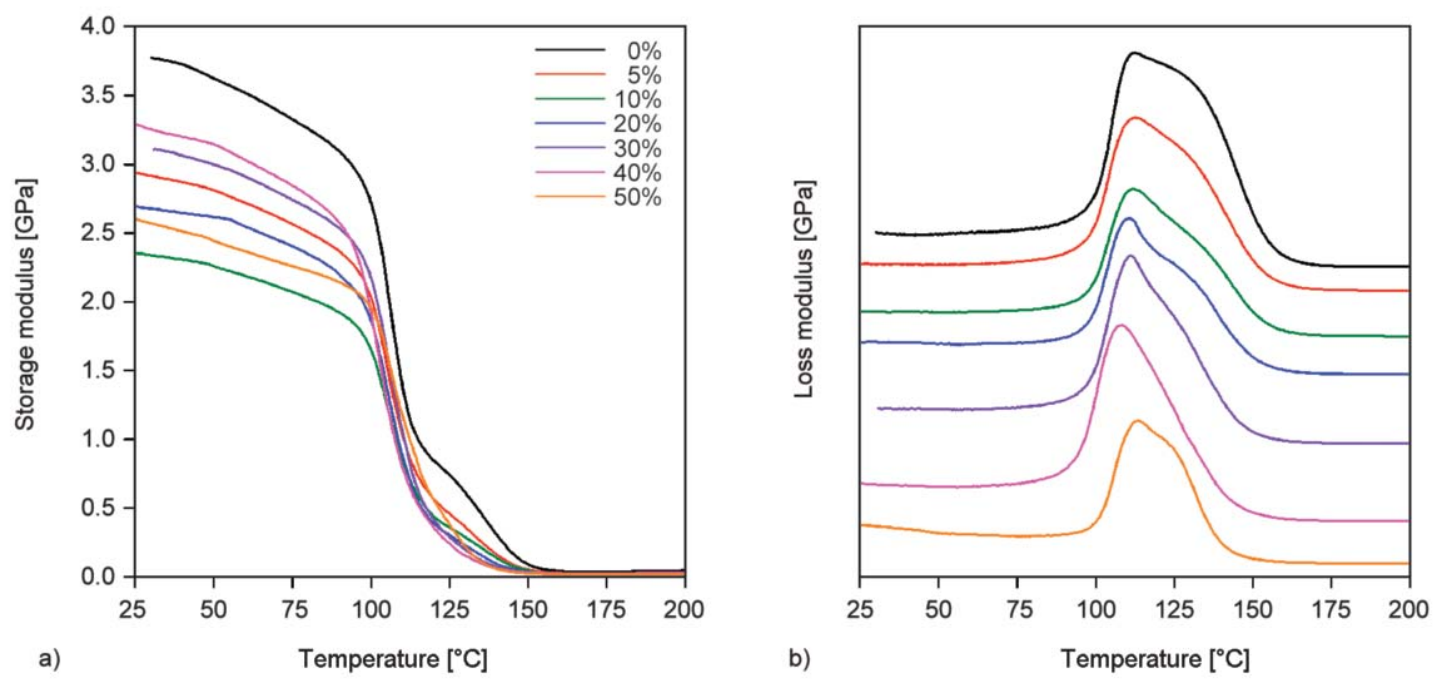

Figure 12. The storage (a) and loss modulus (b) of epoxy specimen.
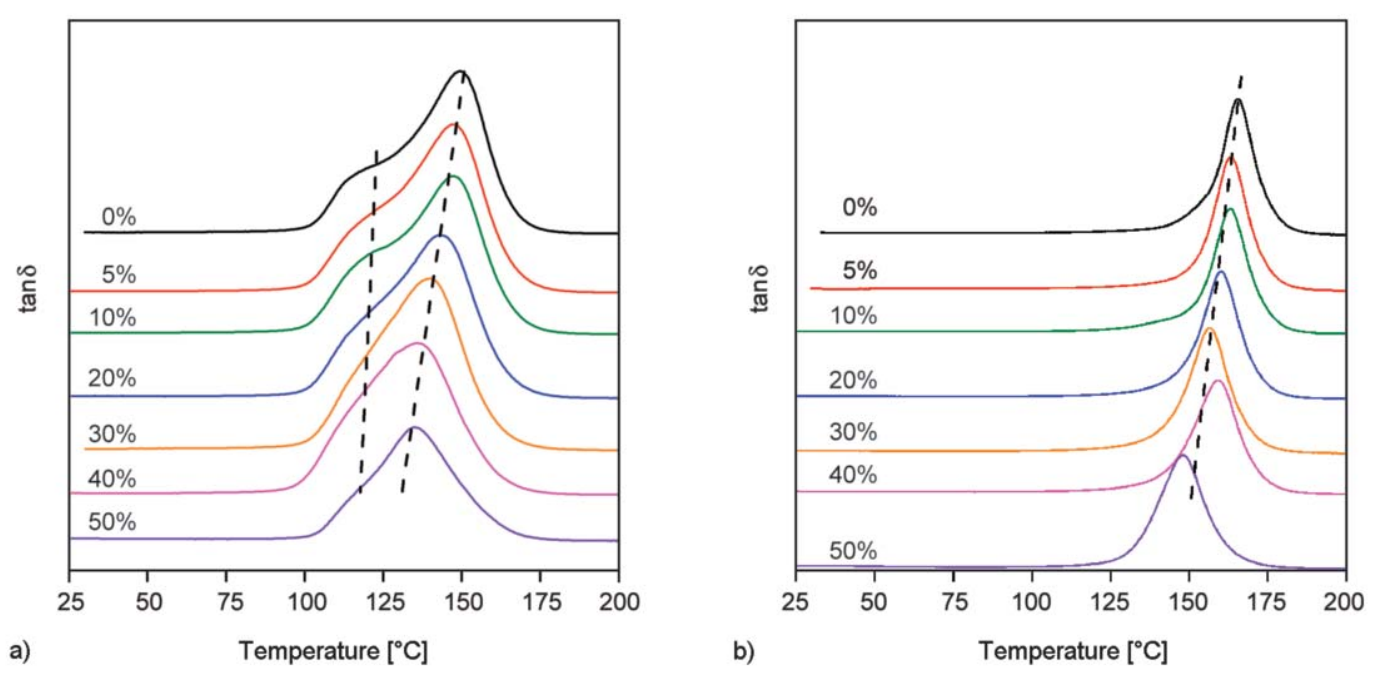

Figure 13. The $\tan \delta$ curves of epoxy specimen before (a) and after post-curing (b).

curves indicated this (Figure 12b, Figure 13a). In both cases peaks with shoulders can be observed in the $100-160^{\circ} \mathrm{C}$ interval. The peak of a $\tan \delta$ curve is associated with the glass transition temperature of a sample. The registered peaks shifted to lower temperatures with the concentration of the PET:IPD 1:2 in the cross-linker solutions, thus the glass transition temperature decreased. The main peak shifted at a greater extent than the shoulder peak, the shoulder peak became less-well defined. Both the storage-, loss modulus and their ratio, the tan $\delta$ indicated a more uniform structure with higher PET:IPD 1:2 concentrations. As we have assumed, the cross-linked structure improved, became more perfect at the same curing conditions due to the catalytic effect of the raw aminolysis product.

The presence of longer terephthal amide diamines resulted in the decrease of the glass transition temperature. The longer cross-linker molecules decreased the cross-link density of the resins, and as their concentration increased their effect became more dominant. A slight increase in the storage modulus was detected above $150^{\circ} \mathrm{C}$ that indicated post-curing during measurements. The effect of post-curing was investigated with DMA on post-cured specimens (170-180 ${ }^{\circ} \mathrm{C}$ for 1 hour) (Figure 13b). The glass transition temperature followed a near-linear decreasing tendency in all cases (Figure 14). The glass transition temperature as expected increased with post-curing. The glass transition temperature of the post-cured specimen correlated with $T_{\mathrm{g}}$ values determined by DSC measurements. The calculated cross-link density of the samples scattered with the increasing concentration of the reaction product due to post curing during the measurement. The post cured specimens showed a clear decreasing tendency in cross-link density with the concentration of the solutions. The $\tan \delta$ values decreased with post curing (Table 4 ). The 


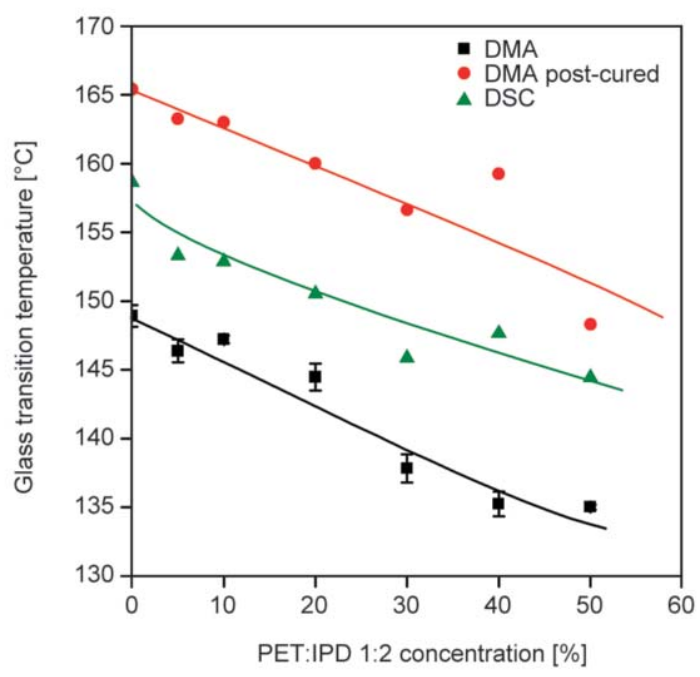

Figure 14. The glass transition temperature determined with DMA and DSC measurements.

cured specimens showed good thermal stability. The thermal degradation occurred near $350-360^{\circ} \mathrm{C}$.

\subsection{Mechanical properties}

The standard tensile tests and instrumented impact resistance measurements were conducted to characterize the mechanical properties of the moulded epoxy specimens (Table 5). The test temperature was far below the $T_{\mathrm{g}}$ of the specimens. Thus, the data were expected to scatter and mostly depend on the flaws of the moulding. Due to the increasing initial viscosity of the resin systems the degassing became less-effective. The more concentrated the cross-linker solution was the more bubbles remained within the resin mixture. In the case of the 40 and $50 \%$ specimens near flawless specimens could not be obtained. These bubbles acted as flaws during mechanical testing and decreased the mechanical properties. In future studies and applications, low molecular weight reactive diglycidyl-ether diluents will be needed to lower the initial
Table 5. Tensile test data of the epoxy specimen.

\begin{tabular}{|c|c|c|c|}
\hline $\begin{array}{c}\text { PET:IPD 1:2 } \\
\text { solution } \\
\text { concentration } \\
{[\%]}\end{array}$ & $\begin{array}{c}\text { Young's } \\
\text { modulus } \\
{[\mathbf{G P a}]}\end{array}$ & $\begin{array}{c}\text { Tensile } \\
\text { strength } \\
{[\mathbf{M P a}]}\end{array}$ & $\begin{array}{c}\text { Elongation at } \\
\text { break } \\
{[\%]}\end{array}$ \\
\hline 0 & $3.58 \pm 0.04$ & $67.56 \pm 15.77$ & $2.64 \pm 0.58$ \\
\hline 5 & $3.42 \pm 0.14$ & $68.45 \pm 4.49$ & $3.13 \pm 1.82$ \\
\hline 10 & $3.56 \pm 0.11$ & $67.65 \pm 4.49$ & $2.51 \pm 1.19$ \\
\hline 20 & $3.55 \pm 0.12$ & $67.86 \pm 5.15$ & $2.46 \pm 0.60$ \\
\hline 30 & $3.29 \pm 0.21$ & $45.37 \pm 4.50$ & $1.60 \pm 0.25$ \\
\hline 40 & $3.67 \pm 0.10$ & $63.75 \pm 1.74$ & $2.31 \pm 0.11$ \\
\hline 50 & $3.02 \pm 0.12$ & $27.47 \pm 17.45$ & $3.21 \pm 3.68$ \\
\hline
\end{tabular}

viscosity of the resin mixture to insure flawless moulding. In this study no reactive diglycidyl-ether diluents were used to consistently report the properties of the cross-linked resins. As expected from an epoxy resin the specimen showed rigid behavior. The impact test showed no significant difference between the different resin mixtures (Figure 15). The pure IPD cross-linked samples had the highest impact resistance due to the lack of bubbles in the specimens.

\section{Conclusions}

The purpose of this study was to investigate the use of raw aminolysis products as cross-linking agents for epoxy resins. The authors proposed the accelerative nature of the EG side product, and the terephthal-amide-diamine main products during the epoxy curing reaction.

The aminolysis of PET was carried out with an epoxy hardener, isophoron-diamine. The raw reaction product was further used without any purification steps. The chemical structure of the produced terephthalic-amide-diamines was identified with NMR measurements. Full assignation of the spectra was done based on the correlative 2D-NMR spectra $\left({ }^{1} \mathrm{H}-{ }^{1} \mathrm{H}\right.$ COSY, ${ }^{1} \mathrm{H}-{ }^{1} \mathrm{H}$ NOESY, ${ }^{1} \mathrm{H}_{-}{ }^{13} \mathrm{C}$ HSQC,${ }^{1} \mathrm{H}_{-}{ }^{13} \mathrm{C}$ HMBC

Table 4. Storage modulus, tan $\delta$ and cross-link density of the epoxy specimens determined with DMA.

\begin{tabular}{|c|c|c|c|c|c|c|c|c|}
\hline & \multicolumn{4}{|c|}{ Cured } & \multicolumn{4}{|c|}{ Post-cured } \\
\hline & \multicolumn{2}{|c|}{ Storage modulus } & \multirow{3}{*}{$\tan \delta$} & \multirow{2}{*}{ Cross-link density } & \multicolumn{2}{|c|}{ Storage modulus } & \multirow{3}{*}{$\tan \delta$} & \multirow{2}{*}{ Cross-link density } \\
\hline & $\left(40^{\circ} \mathrm{C}\right)$ & $\left(200^{\circ} \mathrm{C}\right)$ & & & $\left(40^{\circ} \mathrm{C}\right)$ & $\left(200^{\circ} \mathrm{C}\right)$ & & \\
\hline & [GPa] & [MPa] & & {$\left[\mathrm{mol} \cdot \mathrm{m}^{-3}\right]$} & [GPa] & [MPa] & & {$\left[\mathrm{mol} \cdot \mathrm{m}^{-3}\right]$} \\
\hline $0 \%$ & 3.523 & 36.35 & 1.204 & 9240.5 & 2.888 & 31.81 & 0.997 & 8086.4 \\
\hline $5 \%$ & 2.757 & 25.21 & 1.199 & 6408.6 & 2.719 & 29.49 & 0.985 & 7496.6 \\
\hline $10 \%$ & 2.847 & 27.52 & 1.090 & 6995.8 & 2.429 & 27.06 & 0.922 & 6878.9 \\
\hline $20 \%$ & 1.795 & 26.43 & 1.199 & 6718.7 & 2.504 & 26.17 & 0.938 & 6652.7 \\
\hline $30 \%$ & 3.045 & 25.56 & 1.230 & 6497.6 & 2.667 & 24.96 & 0.924 & 6345.1 \\
\hline $40 \%$ & 1.886 & 26.05 & 1.140 & 6622.1 & 2.592 & 23.64 & 0.840 & 6009.5 \\
\hline $50 \%$ & 2.615 & 16.80 & 0.826 & 4270.7 & 2.561 & 16.91 & 0.837 & 4298,7 \\
\hline
\end{tabular}



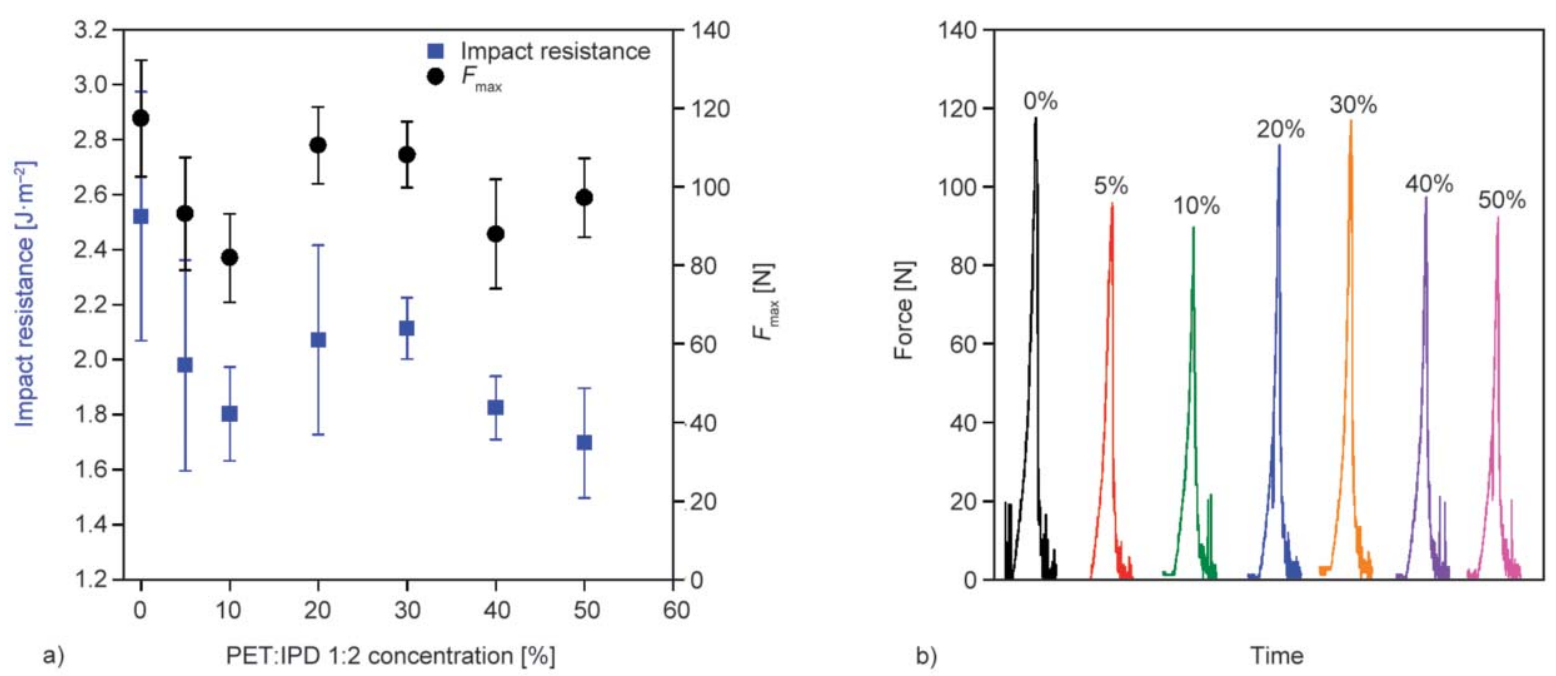

Figure 15. The impact resistance, maximum registered force at failure (a) and fractographs (b) of the epoxy specimens.

and ${ }^{1} \mathrm{H}-{ }^{15} \mathrm{~N}$ HMBC). Cross linker solutions of the aminolysis product with IPD were prepared $(0$ 50 weight $\%$ ) and used for the curing of the epoxy resins. The solutions were easy to prepare with additional IPD during or right after the aminolysis process. The curing of the epoxy resin was characterized with isothermal $\mathrm{DSC}\left(\right.$ at $90^{\circ} \mathrm{C}$ ) and rotational viscosimetry $\left(\right.$ at $\left.50^{\circ} \mathrm{C}\right)$ measurements. The reaction heat was found to increase with the concentration of the crosslinker solution. The rotational viscosimetry measurements showed a significant acceleration effect of the aminolysis product on cross-linking. The catalytic effect of the terephthal-amide-diamines was demonstrated using model IPD-EG solutions. The results clearly proved the catalytic behavior of the amides, it clearly exceeded the model IPD EG solutions. The results of the thermomechanical measurements showed decrease in the glass transition temperature of the epoxy resins. The longer terephthal-amide molecules, compared to IPD formed longer links between the polymeric chains. The concentration of the aminolysis product increased the number of longer crosslinks, thus the cross-link density decreased. The mechanical properties at room temperature showed no significant change with the concentration of the cross linker solutions. The resins showed rigid behavior, any loss in mechanical properties can be attributed to the flaws (bubbles) from the preparation and curing processes.

The findings of this study showed a simpler, greener way to process and use PET aminolysis products. The lack of expensive purification steps even proved to be advantageous during the epoxy curing reaction, and provided a faster curing for IPD based epoxy systems.

\section{Acknowledgements}

Levente Kárpáti was supported by the ÚNKP 17-3-I New National Excellence Program of the Ministry of Human Capacities. The authors thank János Móczó and Károly Renner from our department for their help with the mechanical properties evaluation and measurements.

\section{References}

[1] Cruz Sanchez F. A., Boudaoud H., Hoppe S., Camargo M.: Polymer recycling in an open-source additive manufacturing context: Mechanical issues. Additive Manufacturing, 17, 87-105 (2017).

https://doi.org/10.1016/j.addma.2017.05.013

[2] Geyer R., Jambeck J. R., Law K. L.: Production, use, and fate of all plastics ever made. Science Advances, $\mathbf{3}$, e1700782/1-e1700782/5 (2017). https://doi.org/10.1126/sciadv.1700782

[3] Ragaert K., Delva L., van Geem K.: Mechanical and chemical recycling of solid plastic waste. Waste Management, 69, 24-58 (2017).

https://doi.org/10.1016/j.wasman.2017.07.044

[4] Maris J., Bourdon S., Brossard J-M., Cauret L., Fontaine L., Montembault V.: Mechanical recycling: Compatibilization of mixed thermoplastic wastes. Polymer Degradation and Stability, 147, 245-266 (2018). https://doi.org/10.1016/j.polymdegradstab.2017.11.001

[5] Duarte I. S., Tavares A. A., Lima P. S., Andrade D. L. A. C. S., Carvalho L. H., Canedo E. L., Silva S. M. L.: Chain extension of virgin and recycled poly(ethylene terephthalate): Effect of processing conditions and reprocessing. Polymer Degradation and Stability, 124, 26-34 (2016).

https://doi.org/10.1016/j.polymdegradstab.2015.11.021 
[6] Hamad K., Kaseem M., Deri F.: Recycling of waste from polymer materials: An overview of the recent works. Polymer Degradation and Stability, 98, 28012812 (2013).

https://doi.org/10.1016/j.polymdegradstab.2013.09.025

[7] Bahlouli N., Pessey D., Raveyre C., Guillet J., Ahzi S., Dahoun A., Marie J.: Recycling effects on the rheological and thermomechanical properties of polypropylene-based composites. Materials and Design, 33, 451458 (2012).

https://doi.org/10.1016/j.matdes.2011.04.049

[8] Mehat N. M., Kamaruddin S.: Optimization of mechanical properties of recycled plastic products via optimal processing parameters using the Taguchi method. Journal of Materials Processing Technology, 211, 1989 1994 (2011).

https://doi.org/10.1016/j.jmatprotec.2011.06.014

[9] da Costa H. M., Ramos V. D., de Oliveira M. G.: Degradation of polypropylene (PP) during multiple extrusions: Thermal analysis, mechanical properties and analysis of variance. Polymer Testing, 26, 676-684 (2007). https://doi.org/10.1016/j.polymertesting.2007.04.003

[10] Żenkiewicz M., Richert J., Rytlewski P., Moraczewski K., Stepczyńska M., Karasiewicz T.: Characterisation of multi-extruded poly(lactic acid). Polymer Testing, 28, 412-418 (2009).

https://doi.org/10.1016/j.polymertesting.2009.01.012

[11] Al-Sabagh A. M., Yehia F. Z., Harding D. R. K. K., Eshaq G., ElMetwally A. E.: $\mathrm{Fe}_{3} \mathrm{O}_{4}$-boosted MWCNT as an efficient sustainable catalyst for PET glycolysis. Green Chemistry, 18, 3997-4003 (2016).

https://doi.org/10.1039/C6GC00534A

[12] Stoski A., Viante M. F., Nunes C. S., Muniz E. C., Felsner M. L., Almeida C. A. P.: Oligomer production through glycolysis of poly(ethylene terephthalate): effects of temperature and water content on reaction extent. Polymer International, 65, 1024-1030 (2016). https://doi.org/10.1002/pi.5146

[13] Suo Q., Zi J., Bai Z., Qi S.: The glycolysis of poly(ethylene terephthalate) promoted by metal organic framework (MOF) catalysts. Catalysis Letters, 147, 240-252 (2017).

https://doi.org/10.1007/s10562-016-1897-0

[14] Jehanno C., Flores I., Dove A. P., Müller A. J., Ruipérez F., Sardon H.: Organocatalysed depolymerisation of PET in a fully sustainable cycle using thermally stable protic ionic salt. Green Chemistry, 20, 1205-1212 (2018).

https://doi.org/10.1039/c7gc03396f

[15] Guo Z., Lindqvist K., de la Motte H.: An efficient recycling process of glycolysis of PET in the presence of a sustainable nanocatalyst. Journal of Applied Polymer Science, 135, 6-11 (2018).

https://doi.org/10.1002/app.46285
[16] Kárpáti L., Szarka G., Hartman M., Vargha V.: Oligoester and polyester production via acido-alcoholysis of PET waste. Periodica Polytechnica Chemical Engineering, 62, 336-344 (2018). https://doi.org/10.3311/PPch.11513

[17] Jamdar V., Kathalewar M., Sabnis A.: Depolymerization study of PET waste using aminoethylethanolamine and recycled product application as polyesteramide synthesis. Journal of Polymers and the Environment, 26, 2601-2618 (2018). https://doi.org/10.1007/s10924-017-1149-4

[18] Teotia M., Tarannum N., Soni R. K.: Depolymerization of PET waste to potentially applicable aromatic amides: Their characterization and DFT study. Journal of Applied Polymer Science, 134, 45153/1-45153/10 (2017). https://doi.org/10.1002/app.45153

[19] More A. P., Kute R. A., Mhaske S. T.: Chemical conversion of PET waste using ethanolamine to bis(2-hydroxyethyl) terephthalamide (BHETA) through aminolysis and a novel plasticizer for PVC. Iranian Polymer Journal (English Edition), 23, 59-67 (2014).

https://doi.org/10.1007/s13726-013-0200-0

[20] Fukushima K., Lecuyer J. M., Wei D. S., Horn H. W., Jones G. O., Al-Megren H. A., Alabdulrahman A. M., Alseqailem F. D., McNeil M. A., Rice J. E., Hedrick J. L.: Advanced chemical recycling of poly(ethylene terephthalate) through organocatalytic aminolysis. Polymer Chemistry, 4, 1610-1616 (2013).

https://doi.org/10.1039/C2PY20793A

[21] Eshaq G., ElMetwally A. E.: (Mg-Zn)-Al layered double hydroxide as a regenerable catalyst for the catalytic glycolysis of polyethylene terephthalate. Journal of Molecular Liquids, 214, 1-6 (2016).

https://doi.org/10.1016/j.molliq.2015.11.049

[22] Horn H. W., Jones G. O., Wei D. S., Fukushima K., Lecuyer J. M., Coady D. J., Hedrik J. L., Rice J. E.: Mechanisms of organocatalytic amidation and trans-esterification of aromatic esters as a model for the depolymerization of poly(ethylene) terephthalate. The Journal of Physical Chemistry A, 116, 12389-12398 (2012). https://doi.org/10.1021/jp304212y

[23] Hoang C. N., Dang Y. H.: Aminolysis of poly(ethylene terephthalate) waste with ethylenediamine and characterization of $\alpha, \omega$-diamine products. Polymer Degradation and Stability, 98, 697-708 (2013).

https://doi.org/10.1016/j.polymdegradstab.2012.12.026

[24] Aslzadeh M. M., Sadeghi G. M. M., Abdouss M.: Synthesis and characterization of BHETA based new polyurethanes. Materialwissenschaft und Werkstofftechnik, 41, 682-688 (2010). https://doi.org/10.1002/mawe.201000584 
[25] Tawfik M. E., Ahmed N. M., Eskander S. B.: Aminolysis of poly(ethylene terephthalate) wastes based on sunlight and utilization of the end product [bis(2-hydroxyethylene) terephthalamide] as an ingredient in the anticorrosive paints for the protection of steel structures. Journal of Applied Polymer Science, 120, 2842 2855 (2011).

https://doi.org/10.1002/app.33350

[26] Jehanno C., Pérez-Madrigal M. M., Demarteau J., Sardon H., Dove A. P.: Organocatalysis for depolymerisation. Polymer Chemistry, 10, 172-186 (2018). https://doi.org/10.1039/C8PY01284A

[27] Parab Y. S., Wasekar P. A., Mhaske S. T., Shukla S. R.: Novel synthesis, characterization and application of dibutyrate bis(2-hydroxyethyl) terephthalamide as a plasticizer in PVC compounding. Polymer Bulletin, 71, 2695-2707 (2014).

https://doi.org/10.1007/s00289-014-1218-y

[28] Bulak E., Acar I.: The use of aminolysis, aminoglycolysis, and simultaneous aminolysis-hydrolysis products of waste PET for production of paint binder. Polymer Engineering and Science, 54, 2272-2281 (2014). https://doi.org/10.1002/pen.23773

[29] Palekar V. S., Damle A. J., Shukla S. R.: Synthesis and antibacterial activity of some novel bis-1,2,4-triazolo [3,4-b]-1,3,4-thiadiazoles and bis-4-thiazolidinone derivatives from terephthalic dihydrazide. European Journal of Medicinal Chemistry, 44, 5112-5116 (2009). https://doi.org/10.1016/j.ejmech.2009.07.023
[30] Dutt K., Soni R. K.: Synthesis and characterization of bis-amino ethyl terephthalamide from PET waste and its applications as hardener in DGEBA. International Journal of Plastics Technology, 18, 16-26 (2014).

https://doi.org/10.1007/s12588-014-9071-2

[31] Shechter L., Wynstra J.: Glycidyl ether reactions with alcohols, phenols, carboxylic acids, and acid anhydrides. Industrial and Engineering Chemistry, 48, 86-93 (1956). https://doi.org/10.1021/ie50553a028

[32] Shechter L., Wynstra J., Kurkjy R. P.: Glycidyl ether reactions with amines. Industrial and Engineering Chemistry, 48, 94-97 (1956).

https://doi.org/10.1021/ie50553a029

[33] Smith I. T.: The mechanism of the crosslinking of epoxide resins by amines. Polymer, 2, 95-108 (1961). https://doi.org/10.1016/0032-3861(61)90010-6

[34] Ehlers J-E., Rondan N. G., Huynh L. K., Pham H., Marks M., Truong T. N.: Theoretical study on mechanisms of the epoxy-amine curing reaction. Macromolecules, 40, 4370-4377 (2007). https://doi.org/10.1021/ma070423m

[35] Fedors R. F.: A method for estimating both the solubility parameters and molar volumes of liquids. Polymer Engineering and Science, 14, 147-154 (1974). https://doi.org/10.1002/pen.760140211 